\title{
Racial Discrimination as a Cumulative Risk Factor Affecting Parental Stress on the Psychological Distress of Korean Americans (Both US- and Foreign-Born) amid COVID-19: Structural Equation Modeling
}

\author{
Hyejoon Park ${ }^{1}$. Shinwoo $\mathrm{Choi}^{2} \cdot{\text { Keeyoon } \mathrm{Noh}^{3} \text { [D } \cdot \text { Joo Young Hong }}^{4}$
}

Received: 2 March 2021 / Revised: 4 July 2021 / Accepted: 5 July 2021 / Published online: 19 July 2021

(C) W. Montague Cobb-NMA Health Institute 2021

\begin{abstract}
This study examined the relationships of parental stress and racial discrimination to the psychological distress of Korean Americans (both US- and foreign-born) during the COVID-19 pandemic. It also explored whether racial discrimination moderated the effect of parental stress on psychological distress. Using primary data collected between May 24, 2020, and June 14, 2020, via an online questionnaire, confirmatory factor analysis and structural equation models were conducted on 339 Korean American parents. Results indicated that parental stress and racial discrimination were associated with parental psychological distress. However, when the sample was divided by parental sex, racial discrimination played as a moderator, the interaction of discrimination, and parenting stress was associated with more psychological distress only for mothers. Based on the study results, we recommended that policymakers should consider policies and programs that can reduce racism to make up for the public health crisis associated with COVID-19; clinical practitioners also need to provide appropriate virtual mental/physical health services and interventions that can decrease parental stress and psychological distress amid COVID-19.
\end{abstract}

Keywords COVID-19 $\cdot$ Parental stress $\cdot$ Racial discrimination $\cdot$ Korean Americans $\cdot$ Psychological distress $\cdot$ Structural equation modeling

\section{Introduction}

During the pandemic, numerous studies have discovered that COVID-19 impacts the mental health of residents due to long-

Keeyoon Noh

knoh@ pittstate.edu

Hyejoon Park

hyejoon.park@wmich.edu; juliemongsil@gmail.com

Shinwoo Choi

s_c834@txstate.edu

Joo Young Hong

jooyong.hong98@gmail.com

1 School of Social Work, Western Michigan University, 1903 W. Michigan Ave, Kalamazoo, MI 49008, USA

2 School of Social Work, Texas State University, Encino Hall Building Suite 150A, San Marcos, TX 78666, USA

3 Department of History, Philosophy, and Social Sciences, Pittsburg State University, 1701 S. Broadway, Pittsburg, KS 66762, USA

4 Department of Exceptional, Deaf, and Interpreter Education, University of North Florida, Jacksonville, FL, USA standing self-quarantine and limited social activities [1-4]. In addition, COVID-19 has increased racial discrimination against Asians who have been stigmatized due to the breakout from an East Asian country, the Republic of China. However, there have been only a few studies that began to delve into this situation of Asian immigrants who experienced mental distress due to racial discrimination from dominant countries during COVID-19 [5-8]. Further, not many studies have focused on Korean Americans [3,9], much less Korean American parents who have been stressed while parenting amid COVID-19 due to the shutdown of childcare and public-school systems in the USA. Therefore, this study aims to uncover the psychological distress of Korean American parents who may experience parental stress due to childrearing and/or working, especially focusing on whether pandemic-related racial discrimination affects the psychological distress of these mothers as a cumulative risk factor during COVID-19.

In this paper, overall, we firstly described the background of Korean American population, racial discrimination against Asians, and parental stress during COVID-19 in the literature review. Secondly, using a primary dataset collected amid COVID-19, we examined whether racial discrimination 
would play as a cumulative risk factor on parental stress and psychological distress utilizing structural equation modeling to detect the moderating effect of racial discrimination. Finally, based on our research findings, we discussed and recommended to what extent US policymakers and health practitioners ought to promote the mental health of Korean American parents amid the COVID-19 pandemic.

\section{Literature Review}

\section{The Background of Korean Americans}

Since the 1960s, Korean immigration to the USA has accelerated due to the active relations of politics, economics, and military between South Korea and the USA. After the Immigration Act of 1965 removed restrictions on Asian immigration to the USA, the Korean immigrant population increased significantly from 11,000 in 1960 to 290,000 in 1980. During the following decade, the population doubled to 568,000 , and in 2010, it reached over 1.1 million immigrants [10]. The term Korean Americans include both US-born Koreans and foreign-born Korean immigrants. For the given paper, the primary term that will be used is Korean Americans.

Out of 25 Asian-Pacific subgroups in the USA, Koreans are the fourth group among the six largest Asian population groups: Chinese (2.7 million), Filipino (2.4 million), AsianIndian (1.9 million), Korean (1.2 million), Vietnamese (1.2 million), and Japanese (1.1 million) [11]. Korean immigrants are likely to have higher education and socioeconomic status than other immigrant groups and the overall US-born population. Even though the Korean immigrant population in the USA has reduced over the past few decades, the USA is the nation with the largest Korean immigrant population in the world [10]. Many Koreans are congregated in a few large metropolitans in Southern California. The second area in which the population concentrates is in New York City and the surrounding northern New Jersey, southwestern Connecticut, and eastern Pennsylvania areas. Forty percent of all Korean Americans are located in these two areas [12].

\section{Racial Discrimination Against Asian Individuals}

Even though Asians have gone through racial discrimination in the USA, this discrimination has received less public attention because its main form, racial microaggressions, is more subtle than blunt, purposeful racism [13]. The term racial microaggression originally referred to "subtle, stunning, often automatic, and non-verbal exchanges which are 'put-downs' of Blacks by offenders" [18 p. 25]. This has been expanded to include "brief and commonplace daily verbal, behavioral, and environmental indignities, whether intentional or unintentional, that communicate hostile, derogatory, or negative racial slights and insults to the target person or group" [19 p. 72]. While racial discrimination - a form of overt and covert prejudice and oppression among African American and Hispanic/ Latinx Americans - has been generally acknowledged, that of Asian Americans has been less recognized in society because of the myth of Asians as a model minority and also due to the lessened extent of discriminatory actions directed to this group compared to African Americans and Hispanic/Latinx Americans despite the long historical documentation of racism toward Asian Americans [14]. Specifically, the model minority myth is an assumption indicating a certain group does not need to receive societal support due to their comprisal of high socioeconomic status and its individuals' achievements [15].

Nonetheless, there have been significant research results of negative psychological well-being or mental health (e.g., stress, depression, lower self-esteem, anger) of Asian Americans due to experiencing racial discrimination in daily life, which have been less recognized publicly [14, 16-22]. According to Gee et al. (2007) [23], more than half of the Asian American sample reported being discriminated against due to their race, spoken language, nationality, or accents. In addition, the fact that Asian Americans are viewed as perpetual foreigners regardless of their country of birth also influences the stereotype that Asian Americans are untrustworthy $[24,25]$. Furthermore, many earlier studies attempted to explore the factors associated with Asian Americans' experiences of racial discrimination with special attention to coping and gender differences. For instance, Kuo (1995) found a gender difference in the coping mechanism when Asian men vs. Asian women became victims of racism [26]. In the study, Asian women were more likely to seek emotion-focused support than problem-solving strategies when they experienced racial discrimination. Liang, Alvarez, Juang, and Liang (2007) also found gender differences in reaction toward perceived racial discrimination among Asian men and women. In their study, it was found that men were more likely to report experiencing racism, but women were more likely to utilize support-seeking coping strategies [27]. Additionally, several studies found gender differences among the African American sample; men were more likely to report higher frequencies of racism in their lives, even though both genders experienced a similar level of everyday discrimination [28-31].

However, such subtle racial discrimination against Asian Americans has become more overt since the outbreak of COVID-19 caused many Americans to undergo a financial crisis, social isolation, and fear of disease. Asian Americans have experienced more difficulties than before due to stigma as the origin and spreaders of the COVID-19 disease [32]. At the beginning of the outbreak of COVID-19, images of Asians wearing face masks portrayed in media and newspapers triggered the increase of xenophobia and racism against Asian populations throughout the world [5]. Thirty-nine percent of 
Asian Americans reported experiences of racial discrimination before COVID-19 [8]; however, many Asian Americans reported that they have suffered from more overt racism and racist attacks during the pandemic [10]. Additionally, the Federal Bureau of Investigation (FBI) announced an official warning of hate crimes targeting Asians following the outbreak of the virus [7].

Although it has not been fully assessed, a few studies have uncovered that there were mental health issues due to perceived discrimination amid COVID-19 [6, 33]. For example, during COVID-19, numerous Chinese Americans reported mental health problems after experiencing internalized stigmatization [24], and Asian immigrants-especially those who wore masks - were more likely to perceive discrimination than any other racial groups, which increased mental distress [11].

\section{Parental Stress amid COVID-19}

It is well known that parental stress significantly affects childrearing and parents' psychological distress, which in turn impacts the quality of parenting and increases the potential for child maltreatment [34]. First of all, parental stress results from uncertain events or situations that they cannot control as well as unsupportive family environments [35]. Individual and family level stressors and outside of the family systemsignificant predicaments as a consequence of COVID-19have provided various ranges of stressors to families [34].

The perceived impact of COVID-19 has increased the level of parenting stress, causing psychological distress, including anxiety and depressive symptoms [36]. Such stresses associated with psychological distress can be a risk factor of diminishing parenting skills, decreased response to children's needs, and potential child abuse cases [37]. In particular, several public health efforts, including closing schools, childcare agencies, and many customer service businesses, have resulted in the inability to access supportive and educational services, which may exacerbate stress in many family households during COVID-19 [25].

In fact, social isolation increases susceptibility to stress and negative impacts on mental and physical health [38]. Furthermore, parents who are required to work at home and remain at home with their children may be more vulnerable due to challenges, such as caring for and educating their children at the same time [25]. This situation has drawn attention from educators and professionals due to the high risk of parents' stress and its effect on parenting, and the potential of child abuse and neglect [39]. Over 1.4 billion children are out of school or childcare with no access to outside activities and group sports worldwide due to COVOID-19 [40]. Given the closures of schools and childcare during the pandemic, parents, especially working parents, face increased demands of homeschooling along with the expectations and requirements of working from home. Parents that work in health- care services or essential industries may be more stressed due to a lack of childcare and concerns/stresses related to contamination from the workplace [36].

The Centers for Disease Control and Prevention (2020) stated that other social conditions might worsen the impact of COVID-19-related stressors on overall perceptions of parental stress among minority populations; in particular, COVID-19 is a more significant burden for racial and ethnic minority groups, such as African Americans and Latinx individuals than Whites regarding the rate of illness, hospitalization, and death from COVID-19 [41]. Systematic inequities also contribute to disparities in physical and mental conditions among minority families - in particular, Asians - due to experiencing racism and discrimination amid COVID-19 [25]. That inaccessibility to social service and support, as well as social inequalities, as a result, put minority families at greater risk for increased parental stress during the COVID-19 pandemic [25].

As aforementioned, experiencing racial discrimination can be a significant cumulative risk factor affecting parental stress that is negatively associated with Korean Americans' psychological distress, especially during COVID-19. Therefore, we would like to examine whether racial discrimination plays as a moderating effect on the relationship between Korean Americans' parental stress and psychological distress amid COVID-19. Notably, following the fact that childcare has been a considerable barrier for mothers who have mostly unpaid caregiving responsibilities, especially when their family cannot find affordable childcare [42], we hypothesized that mothers, in general, would have poorer significant relationships with psychological distress than fathers, and additionally, discrimination would have an interactive effect on parents' (in particular, mothers') psychological distress.

\section{Data and Methods}

\section{Data Collection}

The current study collected original data from Korean immigrants, including Korean Americans (i.e., both US-born and foreign-born) in the USA, employing purposive sampling from May 24, 2020, to June 14, 2020. International Review Board was approved at the University of North Florida (IRB\#: 1289431-5). Through emails and posts on online communities for Korean immigrants, the respondents were invited to participate in an online survey. The invitation described the purpose of the study and asked for participants' informed consent for inclusion in the study. All participants were analyzed for informed consent, and their responses were saved anonymously in the data file. The survey provided participants with an option to choose their preferred language between English and Korean. All items in the survey were first translated in both languages by the researchers and then validated by 
external reviewers fluent in both languages. They were culturally and linguistically corrected before being sent out to the participants.

The sample included in the analyses was 342. Among them, three participants chose not to disclose their sex. Their responses were not used for this study since gender is an important factor in our research questions. Thus, our final sample size was 339 included in the analyses.

\section{Measurement}

Psychological distress was measured by a set of 10 questions using the Kessler Psychological Distress Scale (K10) to gauge participants' psychological distress, anxiety, and depression in the most recent 4-week period [43]. Some of the example questions in the item inventory include "During the last 30 days, about how often did you feel tired out for no good reason?" and "During the last 30 days, about how often did you feel nervous?" (from $1=$ none of the time to $5=$ all of the time; $\alpha=0.93$ ). Participants who score below 20 indicate that they have no significant distress. Those who score 20-24 indicate mild distress, those who score 25-29 indicate moderate distress, and those who score 30 and above indicate severe distress and a probable mental disorder [43].

Parental stress was measured using a set of 18 questions, asking about each participant's level of stress from raising their child(ren) [44]. Some examples of the questions include "The behavior of my child(ren) is often embarrassing or stressful to me" and "I feel overwhelmed by the responsibility of being a parent" (from $1=$ Strongly disagree to $5=$ Strongly agree; $\alpha=0.88$ ). Among the items, eight items were reverse coded before the analysis because, unlike the other ten items, these eight items asked participants about their positive feelings or attitudes about raising their child(ren) such as "I am happy in my role as a parent" and "I enjoy spending time with my child(ren)" (originally coded in the questionnaire from $1=$ Strongly disagree to $5=$ Strongly agree).

Racial discrimination was measured using a set of 3 questions asking about each participant's experiences of being disliked or unfairly treated because of their race [45]. An example of one of the questions is "How often do you think people dislike you because you are Asian?" (from 1 = none of the time to $4=$ most of the time; $\alpha=0.91$ ). As stated in the questions, the variable was measured as perceived racial discrimination during the COVID-19 pandemic.

A questionnaire on sociodemographic characteristics was also administered to the participants. These include sex, age, education level, household income, and employment status.

\section{Data Analysis}

Structural equation modeling (SEM) was conducted on AMOS 23 and SPSS 22.0 (SPSS Inc., Chicago, IL, USA) to examine associations among parental stress, perceived racial discrimination, and psychological distress. In order to test these hypotheses, we first presented a bivariate analysis with means and standard deviations for all variables in the analysis. Then we conducted a confirmatory factor analysis (CFA) model to examine whether the observed variables from the questionnaire adequately reflected the latent variables of our interest (i.e., psychological distress, parental stress, and perceived racial discrimination). Once we confirmed our proposed model, we performed structural equation modeling (SEM) to test our hypotheses and to identify associations between the variables. We presented our proposed model as supplementary material with small rectangles indicating measured variables from our survey questionnaires, ovals indicating latent variables from those measured items, and a large rectangle indicating the interaction term between perceived racial discrimination and parental stress on psychological distress.

For the goodness-of-fit for the model, we relied on the following fit measures: the Comparative Fit Index (CFI), the Tucker-Lewis Index (TLI), the Root Mean-Squared Error of Approximation (RMSEA), and the Standardized Root Mean Square Residual (SRMR). We decided to exclude the goodness-of-fit indices such as the chi-square statistic and the Normed Fit Index (NFI) because these are often misled by factors that are not related to actual model specification (e.g., sample size, the number of parameters). A model with CFI and TLI indices above 0.95 and RMSEA and SRMR values below 0.08 are considered a good fit model [46].

\section{Results}

Table 1 displays the descriptive statistics and bivariate correlations for all the variables included in the model. On average, participants scored 18.87 on the Kessler Psychological Distress, 44.01 on the parental stress, and 5.97 on the racial discrimination scale. The participants included about 53\% males and $46 \%$ females, and the average age was 41.19 . Many of them had a bachelor's or graduate degree $(28.4 \%$ and $43 \%$, respectively), and about $75 \%$ of them had a household income of 50,000 USD or more. About $28 \%$ were unemployed, and $72 \%$ had a part- or full-time job.

Psychological distress was positively correlated with parental stress, racial discrimination, and $\operatorname{sex}(r=0.33, p<$ $0.001 ; r=0.32, p<0.001$; and $r=0.31, p<0.001$, respectively), while it was negatively correlated with education and employment status $(r=-0.20, p<0.001$; and $r=-0.12, p<$ 0.05 , respectively). As parents experienced more parental stress and perceived more racial discrimination, the higher psychological distress. In contrast, as parents had higher education levels, they had less psychological distress. There were also differences in psychological distress by sex and 
Table 1 Descriptive statistics and correlations among variables in the model

\begin{tabular}{|c|c|c|c|c|c|c|c|c|c|}
\hline & & 1 & 2 & 3 & 4 & 5 & 6 & 7 & 8 \\
\hline 1 & Psychological distress & 1 & $0.328^{* * * *}$ & $0.318^{* * * *}$ & 0.009 & $0.312^{* * * *}$ & $-0.200^{* * * *}$ & -0.085 & $-0.119^{*}$ \\
\hline 2 & Parental stress & & 1 & $0.264^{\text {***** }}$ & 0.056 & $0.239^{* * * *}$ & $-0.114^{*}$ & -0.063 & $-0.172^{* *}$ \\
\hline 3 & Racial discrimination & & & 1 & $0.124^{*}$ & $0.134^{*}$ & -0.002 & 0.037 & -0.088 \\
\hline 4 & Age & & & & 1 & 0.077 & $-0.339^{* * * *}$ & -0.041 & 0.035 \\
\hline 5 & $\operatorname{Sex}^{1}$ & & & & & 1 & $-0.364^{* * *}$ & $-0.210^{* * *}$ & $-0.455^{* * *}$ \\
\hline 6 & Education $^{2}$ & & & & & & 1 & $0.260^{\text {**** }}$ & $0.118^{*}$ \\
\hline 7 & Income $^{3}$ & & & & & & & 1 & $0.152^{* *}$ \\
\hline 8 & Employment status ${ }^{4}$ & & & & & & & & 1 \\
\hline $\mathrm{M}(\mathrm{SD})$ & & $18.87(6.88)$ & $44.01(9.70)$ & $5.97(1.98)$ & $41.19(6.30)$ & $0.54(0.50)$ & $2.07(0.97)$ & $1.93(0.99)$ & $0.72(0.45)$ \\
\hline Min & & 10 & 22 & 3 & 24 & 0 & 0 & 0 & 0 \\
\hline Max & & 42 & 79 & 11 & 72 & 1 & 3 & 3 & 1 \\
\hline
\end{tabular}

Note: $* p<0.05 ; * * p<0.01 ; * * * p<0.001$

$M$ means; $S D$ standard deviations; Min minimum; Max maximum

${ }^{1} 0=$ male $(53.2 \%) ; 1=$ female $(45.9 \%)$

${ }^{2} 0=$ high school diploma or less $(7.3 \%) ; 1=$ some level of college $(21.3 \%) ; 2=$ bachelor's degree $(28.4 \%) ; 3=$ graduate degree $(43.0 \%)$

${ }^{3} 0=$ less than $\$ 35,000(13.8 \%) ; 1=\$ 35,000-\$ 49,999(11.5 \%) ; 2=\$ 50,000-\$ 99,999(42.6 \%) ; 3=100,000$ or higher $(32.1 \%)$

${ }^{4} 0=$ unemployed $(28.4 \%) ; 1=$ employed $(71.6 \%)$

employment status; females had higher distress than males, and parents employed had lower levels of distress than those who were unemployed. Age and income did not show statistically significant correlations with psychological distress.

We examined the variance inflation factors (VIFs) for all the independent variables in the model and found that the highest value was 1.44. Therefore, we concluded that there was no multicollinearity issue among them [47]. We also tested non-normality with skewness and kurtosis for each measure before performing the SEM analysis. Although it has not been identified as an exact point where the data substantially depart from normality, we relied on the rule of thumb recommended by Curran, West, and Finch (1996) [48]. We found no problematic univariate values higher than 2.0 for skewness nor values higher than 7.0 for kurtosis.

Figure 1 shows the results of the CFA model. The goodness-of-fit model indices indicated a good fit of the data $(\mathrm{CFI}=0.95, \mathrm{TLI}=0.93, \mathrm{RMSEA}=0.04$, and SRMR $=0.06)$. The factor loading values of each item for their respective latent variables were above the acceptable threshold of 0.40 or 0.70 for the conservative limit [49-51], and they were all statistically significant at the 0.001 level except for one of those for parental stress. Although the acceptable strength of the factor loading has been controversially debated in the literature, low factor loading values $(<0.40)$ are not always unfavorable. For a factor, some items may be more distant from the factor than the others and, therefore, have lower values if the items have a theoretically essential part of the factor [49]. We decided to delete the item ("Caring for my child(ren) sometimes takes more time and energy than I have to give") due to low factor loading from the parental stress factor (factor loading $=0.05 ; p=0.79$ ) because taking more time and energy to care for one's child(ren) does not necessarily mean suffering from stress. Other items with factor loadings between 0.10 and $0.40(p<0.001)$ were retained in the factor.

With the modification, we moved to SEM to test our hypotheses. Figures 2 and 3 showed the results of our final models. Our focus in the study, as hypothesized, is the gender difference in the effects of parental stress and perceived racial discrimination on psychological distress. To examine the gender difference, we performed two separate SEM analyses with a group of fathers $(n=157)$ and a group of mothers $(n=182)$ using multigroup analysis. The multigroup analysis allows us to examine two different moderators (i.e., racial discrimination and gender) simultaneously in one SEM model. The goodness-of-fit model indices indicated a good fit of the data $(\mathrm{CFI}=0.96, \mathrm{TLI}=0.95, \mathrm{RMSEA}=0.03$, and $\mathrm{SRMR}=0.07)$. Our Hypothesis 1 was partially supported in the model; the interaction term between parental stress and perceived racial discrimination was not statistically associated with paternal psychological distress (see Fig. 2), while it was statistically significant with maternal psychological distress (see Fig. 3). For paternal psychological distress, only parental stress was statistically significant $(\beta=0.25 ; p<0.01)$.

For maternal psychological distress, we found positive associations with parental stress and perceived racial discrimination. We also found that perceived racial discrimination moderated the effect of parental stress on maternal psychological distress $(\beta=0.19 ; p<0.05, \beta=0.25 ; p<0.01, \beta=0.15 ; p$ 


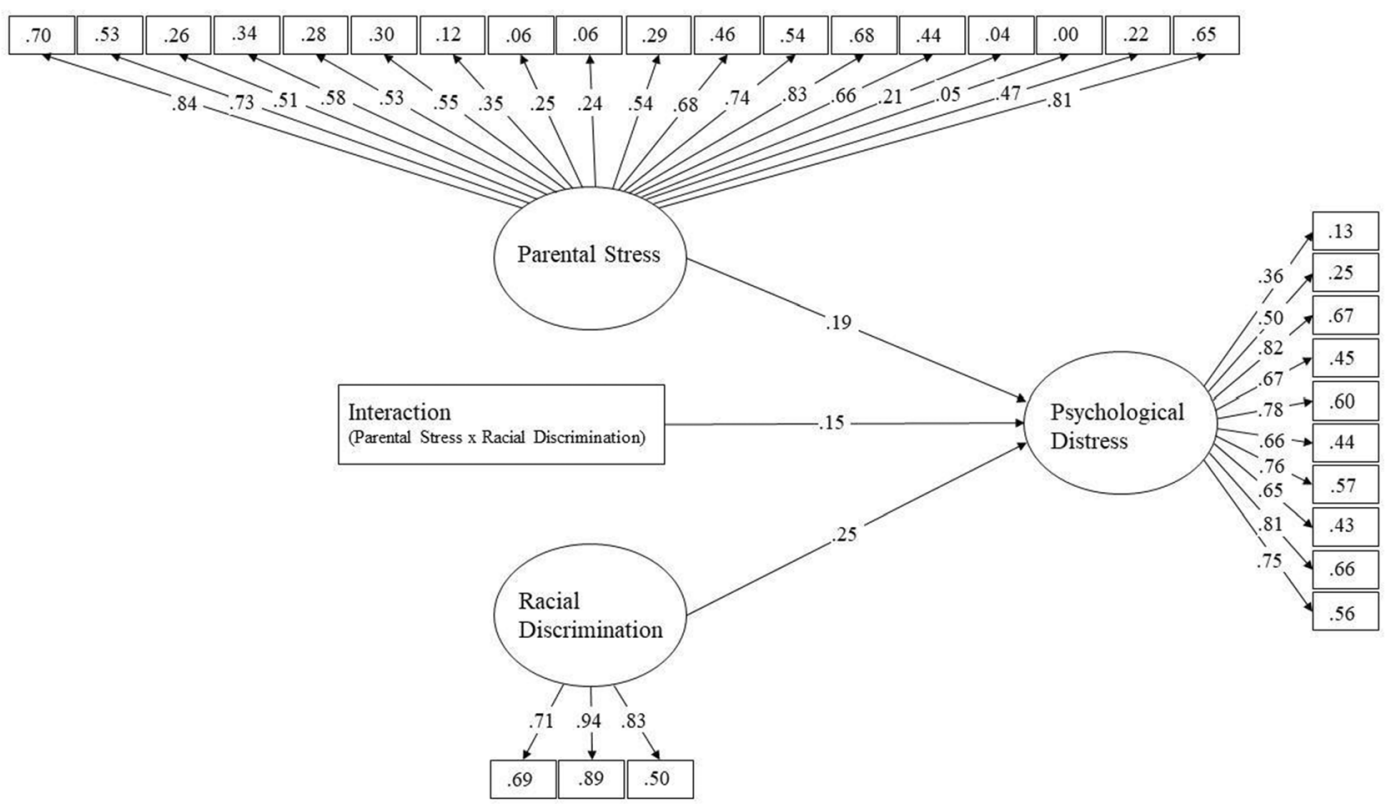

Fig. 1 Results of confirmatory factor analysis for latent constructs in standardized coefficients

$<0.05$, respectively). Our Hypothesis 2 was supported in these two models; there were gender differences in psychological distress affected by parental stress and perceived racial discrimination.

\section{Discussion}

Since the current study's data collection took place amid the COVID-19 pandemic (May-June), we do not have precise information on the target populations' psychological status before the pandemic outbreak. Likewise, how the Korean Americans' perception of racial discrimination has changed over time is also unknown. Since the subtle racism against
Asian Americans has turned into more aggressive forms of racism [52], Asian Americans, including Korean Americans, have also been experiencing a detrimental impact both directly and indirectly. For instance, in 2018, only $3.6 \%$ of Asian Americans reported being seriously psychologically distressed. In contrast, more than 13\% of Asian Americans reported going through severe psychological distress symptoms in April 2020 [16]. Korean Americans in the given study also exhibited a higher psychological distress rate than the general public from the beginning of the pandemic.

Our study's findings showed that parental stress was associated with poorer self-rated psychological distress in Korean American parents. Although the moderating role of racial discrimination on the relationship between parental stress and

Fig. 2 Associations among latent variables for paternal psychological distress $(n=157)$. Note: all coefficients are standardized. $* * p<0.01$

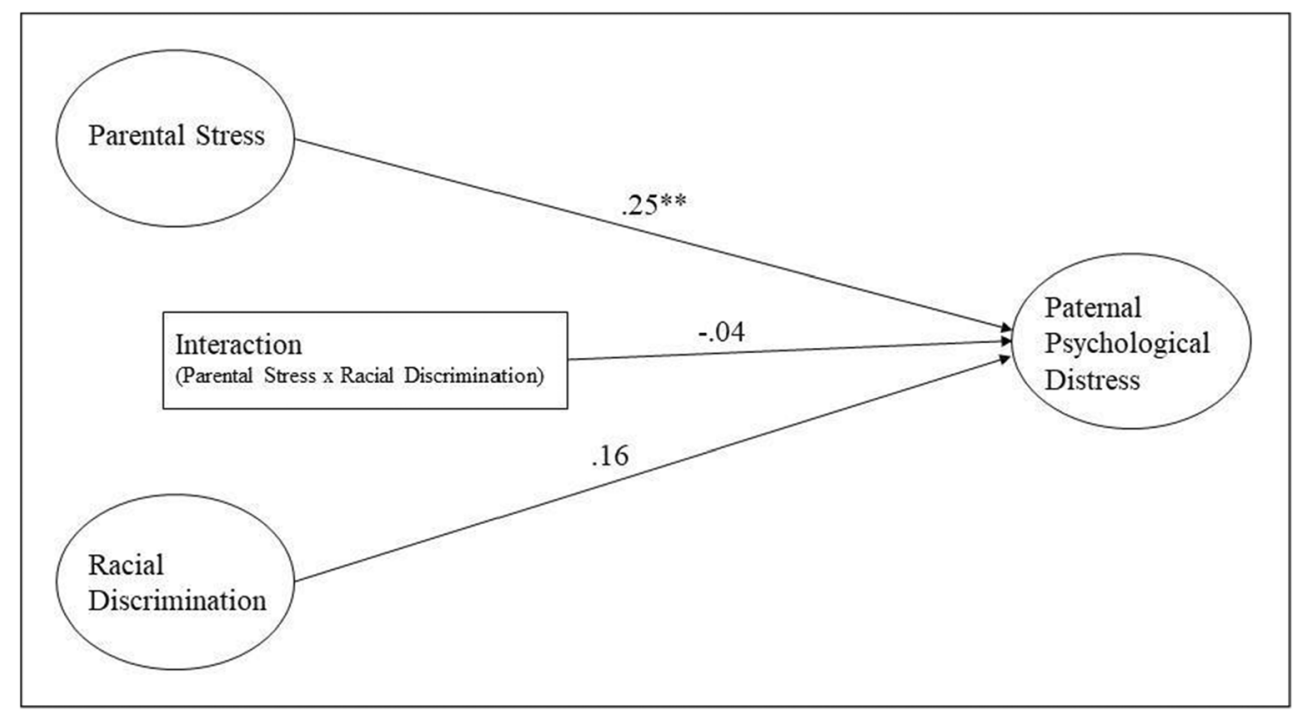


Fig. 3 Associations among latent variables for maternal psychological distress $(n=182)$. Note: all coefficients are standardized. $* p<0.05, * * p<$ 0.01

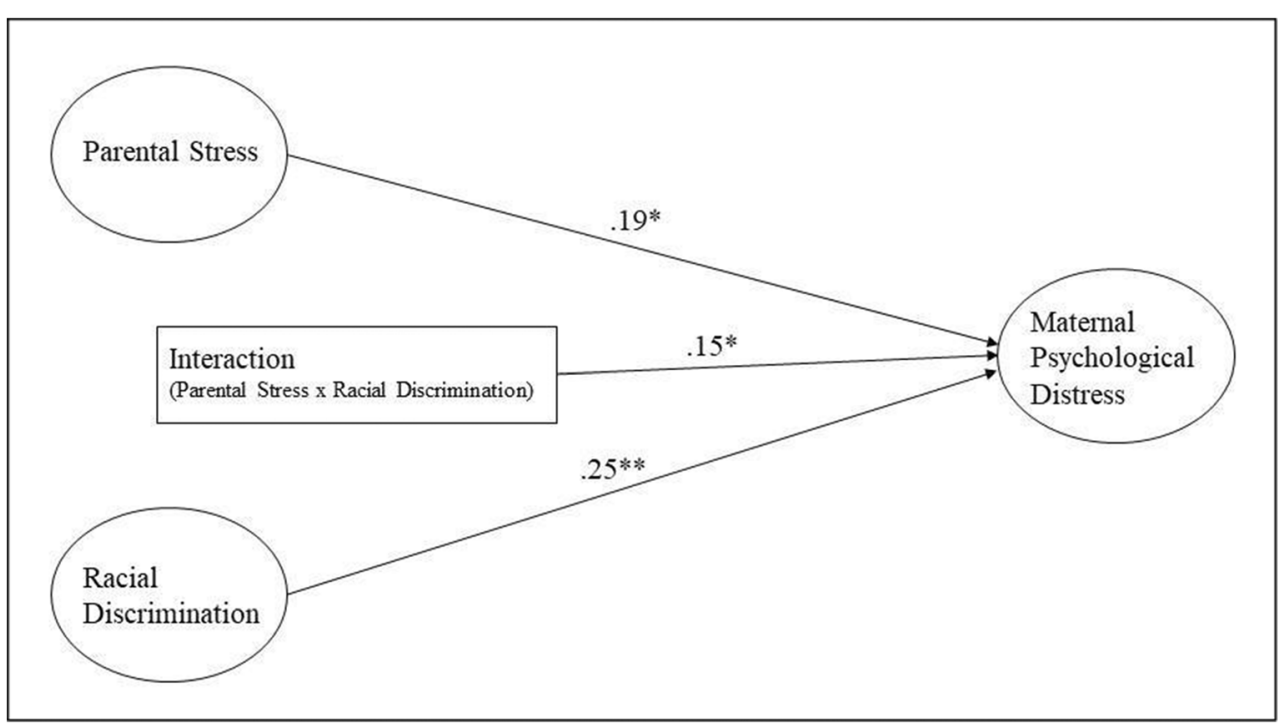

psychological distress was not found in our first model, we found a significant gender difference in the effects of parental stress and perceived racial discrimination on psychological distress. That is to say, not only each single variableparental stress, racial discrimination-affects parents' psychological distress individually, but both variables interact with each other in their association with mothers' psychological distress.

It is known that there are significant gender differences in individuals' psychological distress status and symptoms [53]. For instance, Asian women were more highly distressed than their male counterparts after experiencing racial discrimination [26]. The fact that the given study found a gender difference between parental stress, racial discrimination, and psychological distress is consistent with the previous literature but yielded a novel finding; only for female respondents, perceived racial discrimination moderated the association between parental stress and psychological distress. Fathers' psychological distress was not affected by perceived racial discrimination but only by parental stress. In other words, mothers' psychological distress was more adversely affected than it was not when racial discrimination was cumulated as a risk factor in the association between parental stress and psychological distress of mothers.

\section{Implications}

The current study's findings provide timely implications for practice and policy. Korean immigrant parents in our study reported having high parental stress and psychological distress. Furthermore, this particular association was moderated by the level of racial discrimination for mothers. Amid the current pandemic, thousands of families are experiencing difficult life changes, and parents are doubly burdened by increased childcare responsibilities without the usual support.
In addition, Korean immigrants, along with other Asian Americans, have faced increased racial discrimination since the beginning of COVID-19. Therefore, support for immigrant parents should be provided to address these concerns.

First, in order to serve the mental health needs of immigrant parents amid the pandemic, interventions via telehealth should be developed and delivered. Telehealth is a highly convenient form to provide appropriate mental/physical health services, and it is recommended throughout the world [54]. Social workers targeting immigrant parents can develop tailored mental health programs to provide support in various forms, such as virtual support groups for parents or intensive therapy sessions. Such virtual interventions can also target the children of immigrant parents (e.g., book clubs or social-emotional support groups for children). In this way, parents can take a break from constant childcare, and children can also benefit from social interaction, which is lacking amid the pandemic. Reaching out to immigrant families with various virtual interventions can address and manage increased parental stress and psychological distress at the same time.

Next, experts are stressing that it is vital to create strong group solidarity among various racial minority individuals in order to battle the increase in racism during COVID-19 [55, 56]. It was found that racial minority individuals were empowered if different ethnic/racial groups support each other, and therefore, building solidarity among racial minority groups is highly encouraged in order to overcome the current challenges [42]. Furthermore, at the macro-level, policies to protect Asian Americans against racial hate crimes are necessary. For instance, a recent memorandum by the White House to condemn xenophobia, racism, and intolerance against Asian Americans calls for effective actions from the federal government [57]. Such actions and voices from political leaders are needed to change the current atmosphere against racial minorities, including the Asian American population in the USA. 


\section{Limitations}

Despite the noticeable contributions of the given study, there are still several limitations. First, due to reliance on a purposive sampling strategy, the final sample of the study is not representative of the entire population of Korean American parents in the USA. The final sample represents a relatively high socioeconomic status, and only a tiny percentage of the sample was single parents. Therefore, the final sample cannot represent all Korean American parents' experiences amid the COVID-19 pandemic. Next, since the current study utilized cross-sectional data (collected from May to June 2020), we cannot infer the long-term effects of parental stress and racial discrimination on the respondents' level of psychological distress. As mentioned, since there is no previous data on the target populations' perceived racism, psychological distress, and parental stress, the findings from the current study have limited ability to assume causality between study variables. We cannot compare and support our argument that Korean Americans perceive that they are experiencing more racism than before the pandemic. Therefore, it is recommended that future studies use random sampling techniques in order to recruit a nationally representative sample of the Korean immigrant population in the USA. Collecting data multiple times amid a pandemic in order to capture the phenomenon longer term is also suggested. Conducting a longitudinal data collection will be especially invaluable since the hate crimes against Asian Americans are rapidly increasing a year and a half later since the beginning of the pandemic. Also, the types and damages of hate crimes intensify, including assaults using weapons such as knives, bricks, or guns [58]. Therefore, future studies can unveil the unique characteristics of racism that Asian Americans are experiencing which started to intensify since the COVID-19 pandemic began. In this way, future studies will be able to provide more rigorous and precise findings.

Author Contribution All authors contributed to the study's conception and design.

Funding This COVID-19 dataset was created with support from the National Science Foundation-funded Social Science Extreme Events Research (SSEER) network and the CONVERGE facility at the Natural Hazards Center at the University of Colorado Boulder (NSF award \#1841338).

\section{Declarations}

Conflict of Interest The authors declare no competing interests.

\section{References}

1. Flaherty GT, Nasir N. Reiseangst: travel anxiety and psychological resilience during and beyond the COVID-19 pandemic. J Travel. 2020;27(8).
2. Karașar B, Canli D. Psychological Resilience and Depression during the Covid-19 Pandemic in Turkey. Psychiatria Danubina. 2020;32(2):273-9.

3. Min JJaC, S. Associations between accessibility to health care service, social support, and Korean American's mental health status amid the COVIID-19 pandemic. [Research manuscript]. In press n.a.

4. Rodríguez-Rey R, Garrido-Hernansaiz H, Collado S. Psychological impact and associated factors during the initial stage of the Coronavirus (COVID-19) pandemic among the general population in Spain. Front Psychol. 2020;11:1540.

5. Burton N. Why Asians in masks should not be the "face" of the coronavirus 2020. [cited 2021 March 30]. Available from: https:// www.vox.com/identities/2020/3/6/21166625/coronavirus-photosracism.

6. Liu Y, Finch BK, Brenneke SG, Thomas K, Le PD. Perceived discrimination and mental distress amid the COVID-19 pandemic: evidence from the understanding America study. Am J Prev Med. 2020;59(4):481-92.

7. Margolin J. FBI warns of potential surge in hate crimes against Asian Americans amid coronavirus abc News 2020; 2020. [cited 2021 March 30]. Available from: https://abcnews.go.com/US/fbiwarns-potential-surge-hate-crimes-asian-americans/story?id= 69831920.

8. Ruiz NG, Horowitz, J., and Tamir, C. . Many Black and Asian Americans say they have experienced discrimination amid the COVID-19 outbreak: Pew Research Center; 2020. [cited 2021 March 30]. Available from: https://www.pewsocialtrends.org/ 2020/07/01/many-black-and-asian-americans-say-they-haveexperienced-discrimination-amid-the-covid-19-outbreak/.

9. Choi S, Hong JY, Kim YJ, Park H. Predicting psychological distress amid the COVID-19 pandemic by machine learning: discrimination and coping mechanisms of Korean immigrants in the U.S. Int J Environ Res Public Health. 2020;17(17):6057.

10. O'Connor AaB, J. Korean Immigrants in the United States.: Migration Information Source; 2019. [cited 2021 March 30]. Available from: https://www.migrationpolicy.org/article/koreanimmigrants-united-states-2017.

11. Karger HJ, Stoesz D. American Social Welfare Policy: a pluralist approach 7ed. New Jersey, USA: Pearson Education; 2014.

12. Chang ET. "Korean Americans" Asian-Nation: the landscape of Asian America. 2021. [cited 2021 March 30]. Available from: http://www.asian-nation.org/korean.shtml\#sthash.WUAfhr5g. dpbs.

13. Nadal KL, Wong Y, Sriken J, Griffin K, Fujii-Doe W. Racial Microaggressions and Asian Americans: an exploratory study on within-group differences and mental health. Asian Am J Psychol. 2015;6(2):136-44.

14. Sue DW, Bucceri J, Lin AI, Nadal KL, Torino GC. Racial microaggressions and the Asian American experience. Cultur Divers Ethnic Minor Psychol. 2007;13(1):72-81.

15. Assalone AE, Fann A. Understanding the influence of model minority stereotypes on Asian American community college students. Community College Journal of Research and Practice. 2017;41(7): 422-35.

16. Dolezsar CM, McGrath JJ, Herzig AJ, Miller SB. Perceived racial discrimination and hypertension: a comprehensive systematic review. Health Psychology. 2014;33(1):20-34.

17. Gee GC, Chen J, Spencer MS, See S, Kuester OA, Tran D, et al. Social support as a buffer for perceived unfair treatment among Filipino Americans: differences between San Francisco and Honolulu. American Journal of Public Health. 2006;96(4):677-84.

18. Gee GC, Ponce N. Associations between racial discrimination, limited English proficiency, and health-related quality of life among 6 Asian ethnic groups in California. American Journal of Public Health. 2010;100(5):888-95. 
19. Hwang W-C, Goto S. The impact of perceived racial discrimination on the mental health of Asian American and Latino college students. Cultural Diversity and Ethnic Minority Psychology. 2008;14(4):326-35.

20. Ong AD, Burrow AL, Fuller-Rowell TE, Ja NM, Sue DW. Racial microaggressions and daily well-being among Asian Americans. Journal of Counseling Psychology. 2013;60(2):188-99.

21. Yoo HC, Lee RM. Ethnic identity and approach-type coping as moderators of the racial discrimination/well-being relation in Asian Americans. Journal of Counseling Psychology. 2005;52(4): 497-506.

22. Yoo HC, Lee RM. Does ethnic identity buffer or exacerbate the effects of frequent racial discrimination on situational well-being of Asian Americans? Journal of Counseling Psychology. 2008;55(1): 63-74.

23. Gee GC, Spencer M, Chen J, Yip T, Takeuchi DT. The association between self-reported racial discrimination and 12-month DSM-IV mental disorders among Asian Americans nationwide. Social Science \& Medicine. 2007;64(10):1984-96.

24. Sue S. In search of cultural competence in psychotherapy and counseling. American Psychologist. 1998;53(4):440-8.

25. Sue DW, Bucceri J, Lin AI, Nadal KL, Torino GC. Racial microaggressions and the Asian American experience. 2009.

26. Kuo WH. Coping with racial discrimination: the case of Asian Americans. Ethnic and Racial Studies. 1995;18(1):109-27.

27. Liang CTH, Alvarez AN, Juang LP, Liang MX. The role of coping in the relationship between perceived racism and racism-related stress for Asian Americans: gender differences. Journal of Counseling Psychology. 2007;54(2):132-41.

28. Kwate NOA, Goodman MS. Racism at the intersections: gender and socioeconomic differences in the experience of racism among African Americans. American Journal of Orthopsychiatry. 2015;85(5):397-408.

29. Smith SM, Sun R. Racial discrimination and depressive symptomology: exploring gender and socioeconomic variations among African American parent-child dyads. Fire!!! 2017;3(1): 130-59.

30. English D, Lambert SF, Evans MK, Zonderman AB. Neighborhood racial composition, racial discrimination, and depressive symptoms in African Americans. American Journal of Community Psychology. 2014;54:219-28.

31. Assari S, Moazen-Zadeh E, Caldwell CH, Zimmerman MA. Racial discrimination during adolescence predicts mental health deterioration in adulthood: Gender differences among Blacks. Frontiers in Public Health. 2017;5.

32. Marquardt AaH, J. 'Wuhan virus' language in G7 joint statement factures alliance. 2020. [cited 2021 March 1]. Available from: https:/www.cnn.com/2020/03/25/politics/g7-coronavirusstatement/index.html.

33. Li J, Liang W, Yuan B, Xeng G. Internalized stiagatization, social support, and individual mental health problems in the public health crisis. International Journal of Environmental Research and Public Health. 2020;17.

34. Brown SM, Doom JR, Lechuga-Pena S, Watamura SE, Koppels T. Stress and parenting during the global COCID-19 pandemic. Child Abuse \& Neglect. 2020;110:1-14.

35. Li F, Godinet MT, Arnsberger P. Protective factors among families with children at risk of maltreatment: Follow up early school years. Children and Youth Services Review. 2011;33(1):139-48.

36. $\mathrm{Wu} \mathrm{Q}, \mathrm{Xu} \mathrm{Y}$. Parenting stress and risk of child maltreatment during the COVID-19 pandemic: a family stress theory-informed perspective. Developmental Child Welfare. 2020;2(3):180-96.
37. McPherson AV, McPherson AV, Lewis KM, Lewis KM, Lynn AE, Lynn AE, et al. Predictors of parenting stress for abusive and nonabusive mothers. Journal of Child and Family Studies. 2009;18(1):61-9.

38. Hawkley LC, Cacioppo JT. Loneliness matters: a theoretical and empirical review of consequences and mechanisms. Annals of Behavioral. 2010;40(2):218-27.

39. U.S. Department of Health \& Human Services. Administration on Children, Youth, and Families, Children's Bureau. Child maltreatment 2018. 2020. [cited 2020 March 1]. Available from: https:// www.acf.hhs.gov/sites/default/files/cb/cm2018.pdf.

40. UNESCO 1.37 billion students now home as COVID-19 school closures expand, ministers scale up multimedia approaches to ensure learning continuity 2020 [Available from: https://en.unesco. org/news/137-billion-students-now-home-covid-19-schoolclosures-expand-ministers-scale-multimedia.

41. White A, Liburd LC, Coronado F. Addressing racial and ethnic disparities in COVID-19 among school-aged children: Are we doing enough? 2021. [cited 2021 June 30]. Available from https:// www.cdc.gov/pcd/issues/2021/21_0084.htm

42. Schochet L. The Child Care Crisis is Keeping Women Out of the Workforce. : Center for Amerian Progress; 2019 [cited 2021 Feb 27]. Available from: https://www.americanprogress.org/ issues/early-childhood/reports/2019/03/28/467488/child-carecrisis-keeping-women-workforce/.

43. Kessler RC, Andrews G, Colpe LJ, Hiripi E, Mroczek DK, Normand SLT, et al. Short screening scales to monitor population prevalences and trends in non-specific psychological distress. Psychological Medicine. 2002;32(6):959-76.

44. Berry JO, Jones WH. The parental stress scale: Initial psychometric evidence. Journal of Social and Personal Relationship. 1995;12: 463-72.

45. Vega WA, Zimmerman RS, Warheit GJ, Apospori E, Gil AG. Risk factors for early adolescent drug use in four ethnic and racial groups. American Journal of Public Health (1971). 1993;83(2): $185-9$.

46. $\mathrm{Hu} \mathrm{L}-\mathrm{Z}$, Bentler PM. Cutoff criteria for fit indexes in covariance structure analysis: Conventional criteria versus new alternatives. Structural Equation Modeling: a Multidisciplinary Journal. 1999;6(1):1-55.

47. Myers RH, Myers RH. Classical and modern regression with applications. Belmont, CA: Duxbury press; 1990.

48. Curran PJ, West SG, Finch JF. The robustness of test statistics to nonnormality and specification error in confirmatory factor analysis. Psychological Methods. 1996;1(1):16-29.

49. Hancock GR, Mueller RO. ProQuest. The reviewer's guide to quantitative methods in the social sciences. Milton Park, Abingdon, Oxon. New York: Routledge; 2010.

50. Henson RK, Roberts JK. Use of exploratory factor analysis in published research: common errors and some comment on improved practice. Educational and Psychological Measurement. 2006;66(3): 393-416.

51. Park HS, Dailey R, Lemus D. The Use of Exploratory Factor Analysis and Principal Components Analysis in Communication Research. Human Communication Research. 2002;28(4):562-77.

52. Gao Q, Liu X. Stand against anti-Asian racial discrimination during COVID-19: A call for action. International Social Work. 2021;64(2):261-4.

53. Smith DT, Mouzon DM, Elliott M. Reviewing the assumptions about men's mental health: an exploration of the gender binary. American Journal of Men's Health. 2018;12(1):78-89.

54. (AAFP) AAoFP. Using Telehealth to Care for Patients During the COVID-19 Pandemic 2020 [cited 2020 May 13]. Available from: 
https://www.aafp.org/patient-care/emergency/2019-coronavirus/ telehealth.html.

55. Chong D, Rogers R. Racial solidarity and political participation. Political Behavior. 2005;27(4):347-74.

56. Hoston WT. Black solidarity and racial context: an exploration of the role of black solidarity in U.S. Cities. Journal of Black Studies. 2009;39(5):719-31.

57. Biden J, J.R. Memorandum Condemning and Combating Racism, Xenophobia, and Intolerance Against Asian Americans and Pacific Islanders in the United States. The White House: Briefing Room 2021. Available from: https://www.whitehouse.gov/briefing-room/ presidential-actions/2021/01/26/memorandum-condemning-andcombating-racism-xenophobia-and-intolerance-against-asianamericans-and-pacific-islanders-in-the-united-states/

58. Cabral S. Covid 'hate crimes' against Asian Americans on rise. BBC News. 2021. [cited 2021 May 30]. Available from: https://www. bbc.com/news/world-us-canada-56218684

Publisher's Note Springer Nature remains neutral with regard to jurisdictional claims in published maps and institutional affiliations. 